\title{
Simultaneous NMDA-Dependent Long-Term Potentiation of EPSCs and Long-Term Depression of IPSCs in Cultured Rat Hippocampal Neurons
}

\author{
Miriam Ivenshitz and Menahem Segal \\ Department of Neurobiology, The Weizmann Institute of Science, Rehovot, 76100, Israel
}

\begin{abstract}
A fundamental issue in understanding activity-dependent long-term plasticity of neuronal networks is the interplay between excitatory and inhibitory synaptic drives in the network. Using dual whole-cell recordings in cultured hippocampal neurons, we examined synaptic changes occurring as a result of a transient activation of NMDA receptors in the network. This enhanced transient activation led to a long-lasting increase in synchrony of spontaneous activity of neurons in the network. Simultaneous long-term potentiation of excitatory synaptic strength and a pronounced long-term depression of inhibitory synaptic currents (LTDi) were produced, which were independent of changes in postsynaptic potential and $\mathrm{Ca}^{2+}$ concentrations. Surprisingly, miniature inhibitory synaptic currents were not changed by the conditioning, whereas both frequency and amplitudes of miniature EPSCs were enhanced. LTDi was mediated by activation of a presynaptic $\mathrm{GABA}_{\mathrm{B}}$ receptor, because it was blocked by saclofen and CGP55845 [(2S)-3-\{[(15)-1-(3,4dichlorophenyl)ethyl]amino-2-hydroxypropyl)(phenylmethyl)phosphinic acid]. The cAMP antagonist Rp-adenosine 3' 5' $^{\prime}$-cyclic monophosphothioate abolished all measured effects of NMDA-dependent conditioning, whereas a nitric oxide synthase inhibitor was ineffective. Finally, network-induced plasticity was not occluded by a previous spike-timing-induced plasticity, indicating that the two types of plasticity may not share the same mechanism. These results demonstrate that network plasticity involves opposite affects on inhibitory and excitatory neurotransmission.
\end{abstract}

Key words: LTP; LTD; NMDA; conditioning; activity-dependent plasticity; culture

\section{Introduction}

Activity-dependent modification of neural networks is an essential mechanism for refinement of connections among neurons in the developing brain (Bi and Poo, 1999). Standard models used in the study of long-term plasticity involve an intense activation of a small set of synapses by electrical stimulation of afferent axons, and these studies have contributed greatly to the understanding of elementary mechanisms of neuronal plasticity (Bliss and Lomo, 1973; Malenka and Nicoll, 1999). However, electrical stimulation usually activates only a small fraction of synapses on the recorded neuron and thus is not easily amenable to morphological and chemical analysis. Chemical long-term potentiation (LTP), which circumvents this issue by acting more globally, has evolved recently as a convenient system for studying plasticity. For example, exposure of spontaneously active neural tissue to agents that enhance activation of the synaptic NMDA receptor has been shown to produce a sustained change in network activity (Parker and Grillner, 1999; Krieger et al., 2000; Goldin et al., 2001; Lu et al., 2001; Puopolo and Belluzzi, 2001; Taccola et al.,

Received April 4, 2005; revised Nov. 8, 2005; accepted Dec. 10, 2005.

This research is supported by a grant from the Israel Science Foundation. We thank V. Greenberger for preparation of the cultures.

Correspondence should be addressed to Menahem Segal at the above address. E-mail: menahem. sega@@eizmann.ac.il.

D0I:10.1523/JNEUROSCI.2964-05.2006

Copyright $\odot 2006$ Society for Neuroscience $\quad$ 0270-6474/06/261199-12\$15.00/0
2003; Fujii et al., 2004) and in synaptic morphology (Neuhoff et al., 1999; Goldin and Segal, 2003). However, the relationship between the enhanced network activity and possible changes in synaptic connections between pairs of individual neurons occurring as a result of the induced plasticity has not yet been clarified. For example, what are the sites of induction and expression of this form of plasticity? Likewise, are there any changes in inhibitory synapses that accompany those presumed to take place at the excitatory synapses after activation of the synaptic NMDA receptor? These fundamental questions are addressed in the present study conducted on dissociated cultured hippocampal neurons. We demonstrate that, after a brief NMDA-mediated network conditioning, both excitatory and inhibitory strengths undergo persistent changes that are evident up to $1 \mathrm{~h}$ after the conditioning, whereby long-term potentiation at excitatory synapses (LTPe) and depression at inhibitory synapses (LTDi) take place simultaneously.

\section{Materials and Methods}

Chemicals. DL-2-Amino-5-phosphonopentanoic acid (APV), saclofen, Rpadenosine $3^{\prime}, 5^{\prime}$-cyclic monophosphothioate (Rp-cAMPs), and $N_{\omega}$-nitro-Larginine (L-NNA) were purchased from Sigma (St. Louis, MO), CGP55845 [(2S)-3-\{[(15)-1-(3,4-dichlorophenyl)ethyl] amino-2-hydroxypropyl) (phenylmethyl)phosphinic acid] was from Tocris Bioscience (Ballwin, MO), and forskolin was from Calbiochem (La Jolla, CA). They stored in frozen aliquoted stock solutions until the day of use. APV was added to the hippocampal cultures a minimum of $2 \mathrm{~d}$ before experiments and diluted to a 
final concentration of $50 \mu \mathrm{M}$. Rp-cAMPs and saclofen were each diluted in either the conditioning medium $(\mathrm{CM})$ or intracellular solution (see below) on the day of experiment to a final concentration of $100 \mu \mathrm{M}$. CGP55845 was diluted in the conditioning medium to a final concentration of $3 \mu \mathrm{M}$. Forskolin was diluted in the internal solution to a final concentration of $50 \mu \mathrm{M}$. BAPTA tetra potassium salt (cell impermeant) was purchased from Invitrogen (Carlsbad, CA) and diluted in internal solution (see below) to a final concentration of $30 \mathrm{~mm}$. Tetrodotoxin (TTX) was purchased from Alomone Labs (Jerusalem, Israel).

Cultures. Animal handling was done in accordance with the guidelines published by the Institutional Animal Care and Use Committee of the Weizmann Institute and with the Israeli National guidelines on animal care. Cultures were prepared as detailed previously (Goldin et al., 2001). Briefly, rat pups were decapitated on day of birth (postnatal day 0 ), and their brains were removed and placed in a chilled $\left(4^{\circ} \mathrm{C}\right)$, oxygenated Leibovitz L-15 medium (Invitrogen) enriched with $0.6 \%$ glucose and gentamicin $(20 \mu \mathrm{g} / \mathrm{ml}$; Sigma). Hippocampal tissue was mechanically dissociated after incubation with trypsin $(0.25 \%)$ and DNAase $(50 \mu \mathrm{g} / \mathrm{ml})$ and passed to the plating medium consisting of $5 \%$ heat-inactivated horse serum (HS), $5 \%$ fetal calf serum, and B-27 $(1 \mu \mathrm{l} / 1 \mathrm{ml})$ prepared in minimum essential medium (MEM) Earl salts (Invitrogen), enriched with $0.6 \%$ glucose, gentamicin $(20 \mu \mathrm{g} / \mathrm{ml}$ ), and $2 \mathrm{~mm}$ glutamax (enriched MEM). Approximately $10^{5}$ cells in $1 \mathrm{ml}$ of medium were plated in each well of a 24-well plate, onto a hippocampal glial feeder layer that was grown on the glass for 2 weeks before the plating of the neurons (Papa et al., 1995). Cells were left to grow in the incubator at $37^{\circ} \mathrm{C}, 5 \% \mathrm{CO}_{2}$ for $4 \mathrm{~d}$, at which time the medium was changed to $10 \%$ HS in enriched MEM, plus a mixture of $5^{\prime}$-fluoro-2-deoxyuridine/uridine $(20 \mu \mathrm{g}$ and $50 \mu \mathrm{g} /$ $\mathrm{ml}$, respectively; Sigma), to block glial proliferation. Four days later, the medium was replaced by $10 \%$ HS in MEM, and no additional changes were made.

Electrophysiology. Hippocampal cultures at $10-15$ d in vitro (DIV) were transferred to a recording chamber placed on the stage of a Zeiss (Oberkochen, Germany) Axioscope upright microscope and washed in either a standard recording medium or one containing $50 \mu \mathrm{M}$ APV. Hippocampal neurons were recorded with patch pipettes containing the following (in $\mathrm{mm}$ ): $136 \mathrm{~K}$-gluconate, $10 \mathrm{KCl}, 5 \mathrm{NaCl}, 10$ HEPES, 0.1 EGTA, $0.3 \mathrm{Na}$-GTP, $1 \mathrm{Mg}$-ATP, and 5 phosphocreatine, pH 7.2 (with a resistance in the range of 5-10 M $\Omega$ ). Junction potentials of $\sim 15 \mathrm{mV}$ were left uncompensated. Quality criteria for accepting a recording included $V_{\mathrm{m}}$ of at least $-55 \mathrm{mV}$ and series resistance and capacitance of $<60 \mathrm{M} \Omega$ and $60 \mathrm{pF}$, respectively, which were not changed significantly throughout the recording session. Signals were amplified with Axopatch 200A and Axoclamp-2 amplifiers and recorded with pClamp8 (Axon Instruments, Union City, CA).

To study synaptic connections, dual whole-cell recordings were conducted. Minimal direct current required to evoke an action potential was injected into the presynaptic neuron in current-clamp mode, and an average of 10 postsynaptic responses was recorded in voltage-clamp mode at $10 \mathrm{~s}$ intervals.

When recording spontaneous miniature EPSCs (mEPSCs), $0.5 \mu \mathrm{M}$ TTX was added to the medium, and neurons were clamped at $-60 \mathrm{mV}$. For recording of miniature IPSCs (mIPSCs), $0.5 \mu \mathrm{M}$ TTX, $20 \mu \mathrm{M}$ DNQX, and $50 \mu \mathrm{M} \mathrm{APV} \mathrm{were} \mathrm{added} \mathrm{to} \mathrm{the} \mathrm{recording} \mathrm{medium,} \mathrm{a} \mathrm{CsCl-based}$ intracellular solution was used, and cells were clamped at $-60 \mathrm{mV}$.

Conditioning. APV at $50 \mu \mathrm{M}$ was added to hippocampal neurons at 7-13 DIV for a minimum of $2 \mathrm{~d}$ before the experiment. Cells were transferred to a recording chamber at 10-15 DIV and perfused continuously

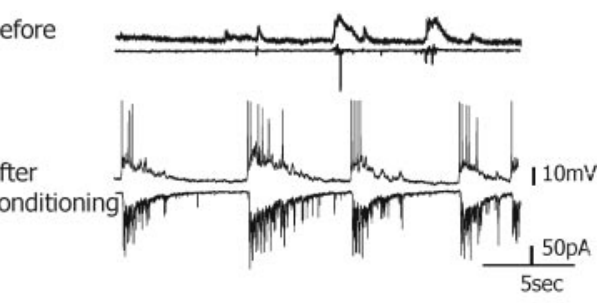

before

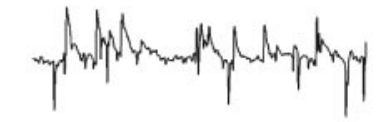

$5 \mathrm{sec}$
$\frac{\left.T^{\pi}\right|^{200 p}}{5 \mathrm{sec}}$

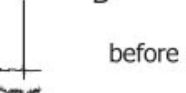

$43 \mathrm{mV}$

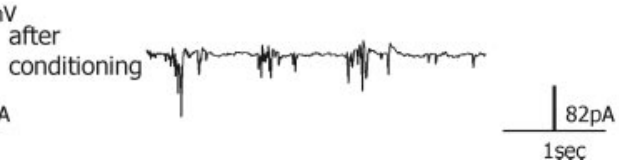
$1 \mathrm{sec}$

Figure 1. Conditioning leads to long-lasting modification of network activity. $\boldsymbol{A}$, Simultaneous whole-cell current-clamp (top

with standard recording medium containing $1 \mathrm{mM} \mathrm{Mg}^{2+}, 2 \mathrm{mM} \mathrm{Ca}^{2+}$, and $50 \mu \mathrm{M} \mathrm{APV}$ at a rate of $1 \mathrm{ml} / \mathrm{min}$. The conditioning involved replacing the standard recording medium by a CM containing $200 \mu \mathrm{m}$ glycine,

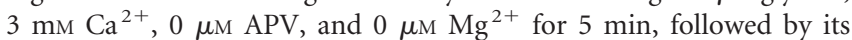
complete washout using the standard APV-containing solution. All electrophysiological recordings were commenced after this washout.

Spike-timing-dependent plasticity (STDP) was produced by generating a spike in the presynaptic neuron, followed by the postsynaptic neuron at a frequency of $10 \mathrm{~Hz}$, paired $10-15$ times every $4 \mathrm{~s}$, as detailed previously (Markram and Segal, 1990). The presynaptic to postsynaptic interval was set at $5 \mathrm{~ms}$ to allow maximal potentiation.

Analysis. The electrophysiological data were summarized and analyzed off-line using Clampfit8, SigmaPlot (SPSS, Chicago, IL), and Origin (Microcal Software, Northampton, MA), followed by $t$ tests or paired $t$ tests, as the case may be. The Clampfit8 program was used to calculate Spearman's correlation coefficients for 1-min-long voltage- and currentclamp whole-cell recordings of spontaneous activity before and $10 \mathrm{~min}$ after the conditioning. mPSC recordings were analyzed off-line using MiniAnalysis software (Synaptosoft, Decatur, GA) with a detection threshold of $9 \mathrm{pA}$.

\section{Results}

\section{Spontaneous activity}

At 10-15 DIV, cultured hippocampal neurons grown in the presence of APV for $2 \mathrm{~d}$ expressed spontaneous action potential discharges and partially synchronized synaptic activity, as detected through simultaneous recordings from adjacent neurons (Fig. $1 A)$. This activity was dramatically changed after a transient, 5 min exposure of the culture to the CM, which favors the activation of synaptic NMDA receptors (Fig. $1 B$ ). The exposure to the $\mathrm{CM}$ led to long-lasting modifications of spontaneous network activity, and the neuronal firing became more synchronized and robust, as seen previously (Goldin et al., 2001). Spearman's correlation coefficient of the spontaneous activity increased from $r=0.28 \pm 0.05$ before to $r=0.58 \pm 0.04$ after conditioning $(n=$ 23 pairs; $p<0.001$ ), indicating the change to a more synchronized network firing pattern. This enhanced network activity was 
A
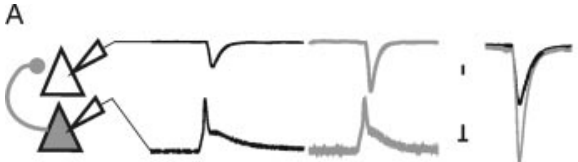

B

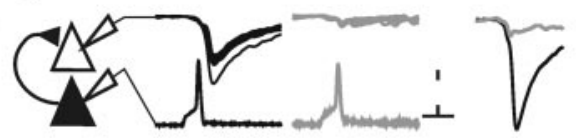

C

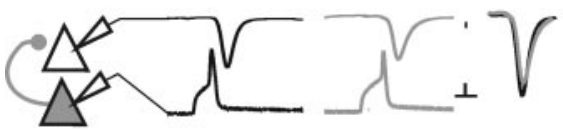

D

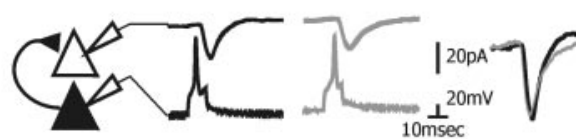

$E$

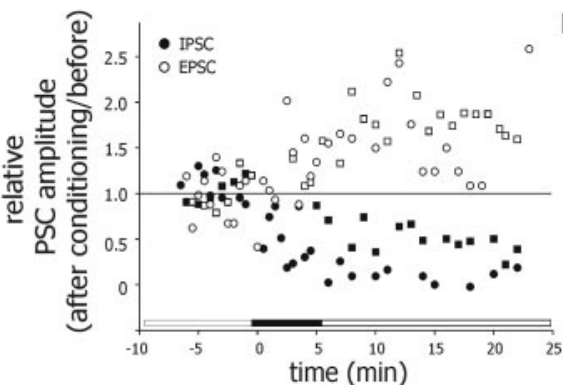

$$
\text { F }
$$

$\mathrm{H}$
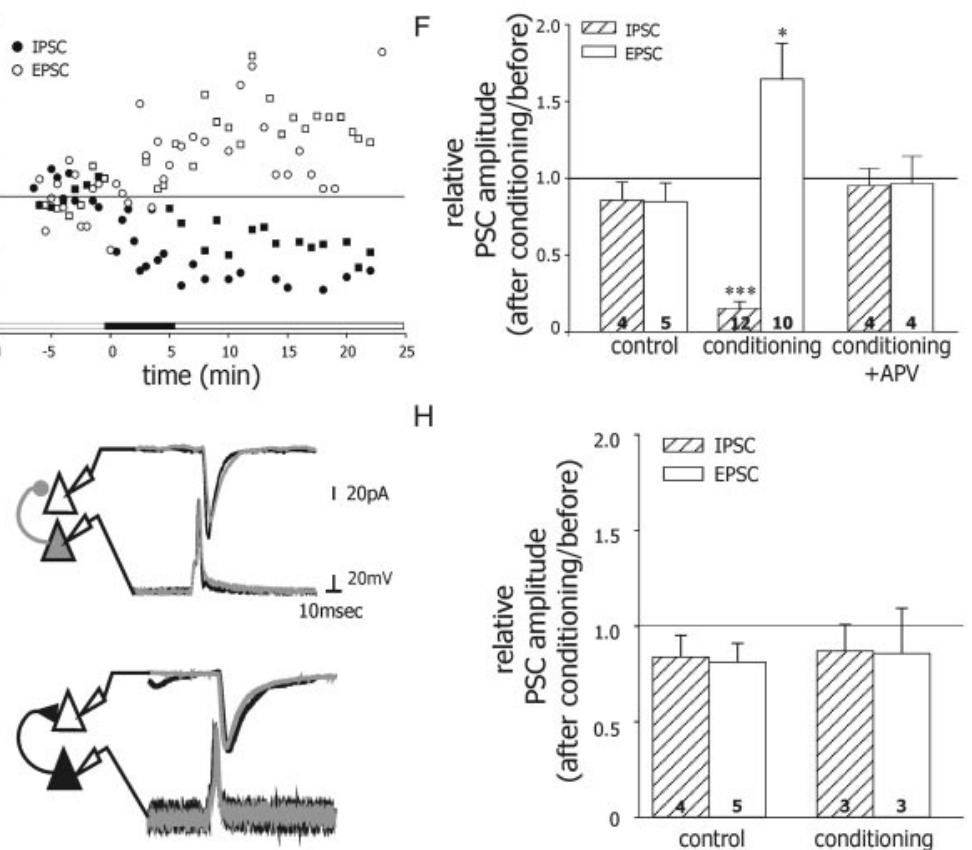

G

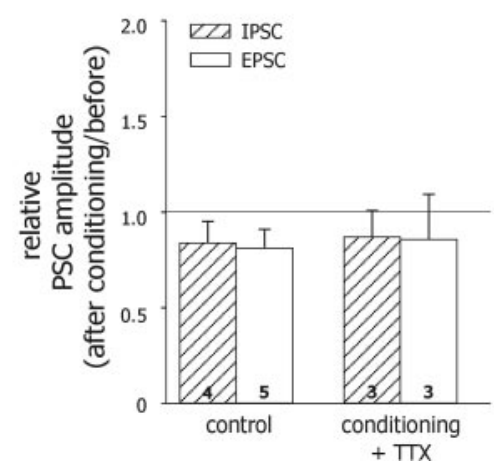

Figure 2. Conditioning leads to LTPe and LTDi. A, Sample illustrations showing evoked presynaptic action potential in currentclamp mode at resting potential and the postsynaptic response of the excitatory synapse (symbolized on the left as a gray circle) recorded in voltage-clamp mode at $-60 \mathrm{mV}$ before (black traces, left) and $10 \mathrm{~min}$ after (gray traces, right) conditioning, showing an increase in EPSC amplitude (LTPe). B, Same as in $\boldsymbol{A}$ but with an inhibitory synapse (black triangle) before and after conditioning, showing decreased IPSC amplitude (LTDi) after conditioning. Top traces are 11 superimposed postsynaptic IPSCs before (black traces, left) and after (gray traces, right) conditioning, showing complete failure of evoked IPSC after conditioning. Bottom traces are evoked presynaptic action potentials. $\boldsymbol{C}, \boldsymbol{D}$, Control experiment showing a minimal rundown response of EPSC (C) and IPSC (D). Calibration: $A-D, 20 \mathrm{pA}, 20 \mathrm{mV}, 10 \mathrm{~ms}$. E, Time course of LTPe and LTDi. Black bar at 0 min on the abscissa indicates a 5 min washin of the $C M$ to activate synaptic NMDA receptors. The rest of the time the medium is a standard APV-containing recording medium. The graph is a summary of two experiments each of both excitatory (open) and inhibitory (filled) transmission (squares and circles) $\boldsymbol{F}$, Summary of all experiments showing relative change in evoked PSC amplitude at $-60 \mathrm{mV}$ for control, conditioning, and conditioning plus APV experiments. Control relative IPSC amplitude was decreased to $0.83 \pm 0.11$ and EPSC amplitude to $0.84 \pm$ 0.11. Conditioning experiments showed a dramatic decrease of relative IPSC amplitude to $0.15 \pm 0.05$ and increase of EPSC amplitude to $1.72 \pm 0.22$. Conditioning plus APV experiments showed no significant change in either evoked IPSCS $(0.92 \pm 0.10)$ or EPSCS $(0.93 \pm 0.17)$. G, Sample illustrations showing evoked presynaptic action potential in current-clamp mode and the postsynaptic response of an excitatory synapse (top) and inhibitory synapse (bottom) before (black traces) and 10 min after (gray traces) TTX-CM, showing neither LTPe nor LTDi. $\boldsymbol{H}$, Summary of all experiments showing that evoked EPSCs remained at $0.86 \pm$ 0.23 and IPSCs at $0.87 \pm 0.14$ relative to control values after TTX-CM. Numbers in bars in this and the following figures indicate number of experiments.

typically persistent for up to $1 \mathrm{~h}$ or as long as healthy recording could be obtained. Control experiments in which APV was retained throughout the experiment as well as in the CM did not show a lasting modification of network activity, and the correlation coefficient of spontaneous activity was left unchanged at $r=$ $0.40 \pm 0.7$ before and $r=0.39 \pm 0.06$ after conditioning $(n=12$ pairs; $p>0.78$; data not shown). APV-naive cultures were also used, with the same negative effects (data not shown). Removal of inhibition by application of the $\mathrm{GABA}_{\mathrm{A}}$ antagonist bicuculline $(10 \mu \mathrm{M})$ showed weak or nonsignificant long-lasting modifica- tions of network activity (data not shown). Removal of $\mathrm{Mg}^{2+}$ alone from the recording solution also caused enhanced spontaneous activity, but these changes were transient and network activity recovered back to control state after replacement of the standard recording solution (Fig. 1C). These experiments indicate that the longterm changes in network activity are indeed attributable to the transient activation of the NMDA receptor.

Spontaneous activity recorded from neurons in culture before and after exposure to the CM consisted of a mixture of excitatory and inhibitory synaptic currents, in addition to action potential discharges. To obtain a clear separation between the synaptic currents, neurons were clamped at $-40 \mathrm{mV}$, at which spontaneous EPSCs are seen as inward currents and IPSCs are seen as outward currents. Under these conditions, spontaneously occurring IPSCs were drastically reduced in amplitude and frequency after conditioning, in contrast to the increase in frequency and rhythmicity of the spontaneous EPSCs (Fig. 1D).

Evoked activity

To analyze the network changes at the synaptic level, we recorded from pairs of neurons in culture and examined the presence of evoked postsynaptic currents between them. The postsynaptic neuron was clamped at three different voltages $(-90$, -60 , and $-30 \mathrm{mV}$ ) to determine the reversal potential and hence the nature of the PSC. In conditioning experiments, the evoked PSCs in response to presynaptically evoked action potentials were recorded at the beginning of the experiment and 10-30 min after complete washout of CM. LTPe was expressed as an increased amplitude of evoked EPSC to $1.72 \pm 0.22$ of baseline values (Fig. $2 A, F)(n=10 ; p<$ 0.05 compared with control). Actual values increased from $69.73 \pm 29.31$ to $120.20 \pm 34.12$ pA. Strikingly, evoked IPSCs decreased to $0.15 \pm 0.05$ of baseline values, what we termed LTDi (Fig. $2 B, F$ ) $(n=12 ; p<0.001$ compared with control). Actual values decreased from $24.12 \pm 5.65$ to $5.34 \pm 1.42 \mathrm{pA}$. In control experiments, the evoked PSCs were recorded at the beginning of the experiment and 10-30 min later, similar to when the recordings were done in the conditioning experiments. Under these conditions, a small excitatory and inhibitory synaptic current rundown to $0.84 \pm 0.11$ and $0.83 \pm 0.11$ of baseline values, respectively, were observed, as can be expected to occur over a period of $\sim 30$ min of patch recording (Fig. $2 C, D, F)(n=4$ and 5 neuron pairs, respectively). Actual EPSC values changed from $111.52 \pm 32.15$ to $104.80 \pm 41.54 \mathrm{pA}$ and IPSC values from $50.06 \pm 21.64$ to $46.29 \pm 19.67 \mathrm{pA}$. When $50 \mu \mathrm{M}$ APV was added 
to the CM (APV-CM), neither LTPe nor LTDi were detected, indicating that conditioning required activation of NMDA receptors, and that it is this transient activation of endogenous NMDA receptor activity that induces both types of plasticity. After APV-CM, evoked EPSCs were $0.93 \pm 0.17$ of baseline values (Fig. $2 F$ ) $(n=4 ; p>0.58)$, and evoked IPSCs were $0.92 \pm 0.10$ of baseline values (Fig. $2 F$ ) $(n=4 ; p>0.59)$.

LTPe and LTDi began to take place almost at the onset of CM, reaching a steady-state level within $5 \mathrm{~min}$ after its washout and lasting for as long as the neurons could be recorded from (Fig. 2E).

To verify that network and action potential-evoked glutamate release (and hence NMDA receptor activity) play a crucial role in the induction of LTPe and LTDi, $0.5 \mu \mathrm{M}$ TTX was applied along with the CM (TTX-CM) and caused a complete cessation of spontaneous activity. During recovery of spontaneous activity after washout of TTX-CM, neither LTPe nor LTDi were induced. Evoked EPSCs remained at $0.86 \pm 0.23$ and IPSCs at $0.87 \pm$ 0.14 relative to baseline values (Fig. $2 G, H$ ) $(n=3$ each; $p>0.84$ and 0.87 , respectively, compared with control). These results further verify that both types of NMDA-dependent plasticity require action potential-evoked glutamate release as well as a large increase network activity, which inherently both lead to NMDA receptor activation.

To characterize the conditioning-evoked changes in synaptic connections, we measured the reversal potential, latency, rise, and decay times of the evoked monosynaptic currents before and after CM (Fig. 3). The reversal potentials for excitatory and inhibitory currents were not changed in a significant manner after $\mathrm{CM}$ (Fig. $3 A, E)(p>0.575$ and 0.13 , respectively). Average latency time for evoked EPSCs was $1.88 \pm 0.20 \mathrm{~ms}$ before and $2.05 \pm 0.26 \mathrm{~ms}$ after CM (Fig. $3 B)(p>0.71)$, and, for evoked IPSCs, the latency time was $1.44 \pm 0.16 \mathrm{~ms}$ before and $1.49 \pm 0.17$ ms after CM (Fig. $3 F)(p>0.43)$. The total EPSC rise time (from baseline to peak) was $4.70 \pm 0.66 \mathrm{~ms}$ before and $5.80 \pm 1.03 \mathrm{~ms}$ after $\mathrm{CM}$ (Fig. 3C) ( $p>0.14)$. EPSC decay times were also unchanged, at $19.0 \pm 3.46 \mathrm{~ms}$ before and $19.7 \pm 2.68 \mathrm{~ms}$ after CM (Fig. $3 D)(p>$ $0.68)$. The total rise time for evoked IPSCs before and after CM was $5.28 \pm 0.47$ and $4.07 \pm 0.34 \mathrm{~ms}$, respectively (Fig. $3 G)(p>0.08)$. The decay time was also left unchanged, at $31.7 \pm 5.27 \mathrm{~ms}$ before and $23.7 \pm 5.78 \mathrm{~ms}$ after CM (Fig. $3 H)(p>0.41)$.

\section{Postsynaptic neuron requirements}

In previous studies, LTP induction in some types of synapses (e.g., the Schaffer collateral synapse in CA1 pyramidal neurons) has been associated with a rise in postsynaptic intracellular $\mathrm{Ca}^{2+}$ concentration (Lynch et al., 1983a; Yang et al., 1999; Lisman, 2001; Patenaude et al., 2003; Wang et al., 2004). To examine this possibility in the neuronal cultures, cell-impermeant BAPTA was added to the intracellular solution to a final concentration of 30 $\mathrm{mM}$ and then introduced into one of the two neurons in the dual-recording configuration. The BAPTA-loaded neuron could either be a presynaptic or a postsynaptic pyramidal neuron or
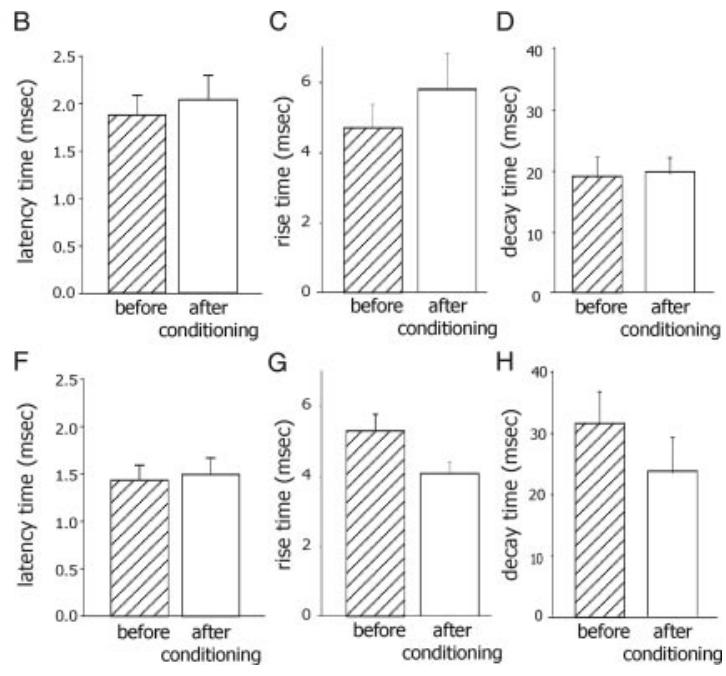

Figure 3. Intrinsic parameters of evoked currents. $\boldsymbol{A}$, Graph showing no significant change in reversal potential of excitatory 作 fter conditioning $C$ Rise times before and after conditioning were $4.70+0.66$ and $5.80+1.03 \mathrm{~ms}$, respectively. $D$, Decay times 列 times before and after conditioning were $5.28 \pm 0.47$ and $4.07 \pm 0.34 \mathrm{~ms}$, respectively. $\boldsymbol{H}$, Decay times were left unchanged, at $31.7 \pm 5.27 \mathrm{~ms}$ before and $23.7 \pm 5.78 \mathrm{~ms}$ after conditioning $(n=6)$.

interneuron. When the presynaptic neuron was loaded with BAPTA, neurotransmitter release was diminished over time because of inability to increase free intracellular $\mathrm{Ca}^{2+}$ concentration. In fact, in both the case of inhibitory and excitatory synaptic transmission, the relative evoked EPSC and IPSC amplitudes were decreased over time to $0.26 \pm 0.09$ and $0.09 \pm 0.01$ of control values, respectively (Fig. $4 A, C)(p<0.05$ relative to control). Clamping the postsynaptic neuron, $\mathrm{Ca}^{2+}$ concentration did not prevent the conditioning-induced LTDi, and the relative evoked IPSC amplitude was reduced to $0.11 \pm 0.07$ after $\mathrm{CM}$, similar to normal conditioning experiments (Fig. $4 B, C$ ) $(p<0.005$ relative to control). The relative evoked EPSC amplitude was increased to $1.47 \pm 0.3$, similar to the experimental group of neurons in which $\mathrm{Ca}^{2+}$ was not clamped (Fig. $4 B, C$ ). These results indicate that a postsynaptic increase in $\mathrm{Ca}^{2+}$ concentration is not necessary for the induction of this NMDA receptor-mediated LTDi in the inhibitory synapse and possibly also for LTPe in the excitatory synapse. This may be similar to other reports in which postsynaptic $\mathrm{Ca}^{2+}$ dependency is addressed, as is the case for hippocampal mossy fiber LTP (Mellor and Nicoll, 2001), although this has been disputable (Yeckel et al., 1999; Kapur et al., 2001; Wang et al., 2004).

Similarly, depolarization of the postsynaptic neuron is not necessary for the induction of LTPe and LTDi. When the postsynaptic neuron was clamped at $-100 \mathrm{mV}$ for the duration of the CM, the evoked EPSC was increased to $1.76 \pm 0.36$ of baseline values after CM (Fig. $4 D, F)(n=8 ; p<0.05)$. Likewise, the evoked IPSC was decreased to $0.28 \pm 0.12$ of baseline values, as in normal conditioning experiments (Fig. $4 E, F)(n=6 ; p<$ 0.05 compared with control).

\section{Spontaneous miniature synaptic currents}

Changes in spontaneous miniature EPSCs and IPSCs can be an indicator for a possible locus of the synaptic modifications occur- 

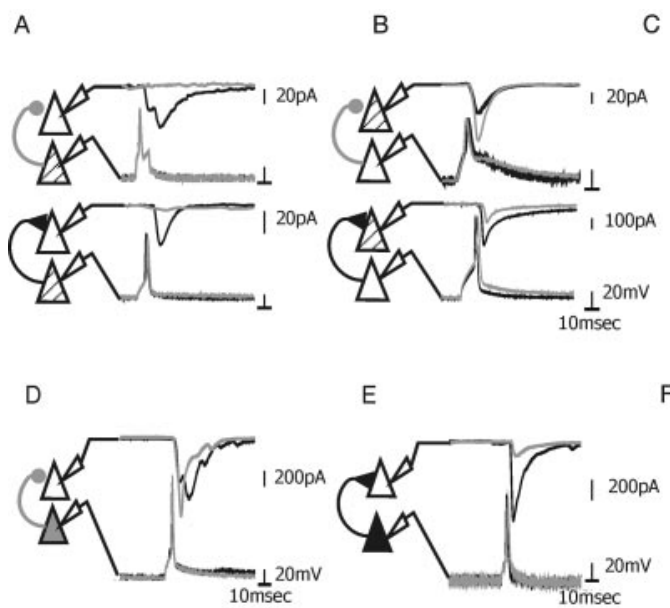

G

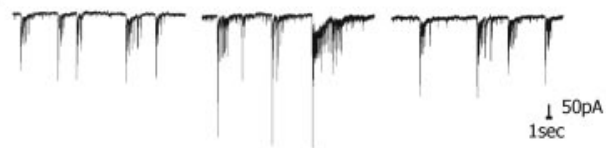

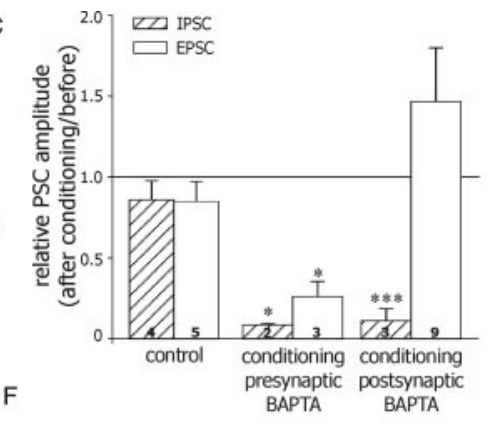

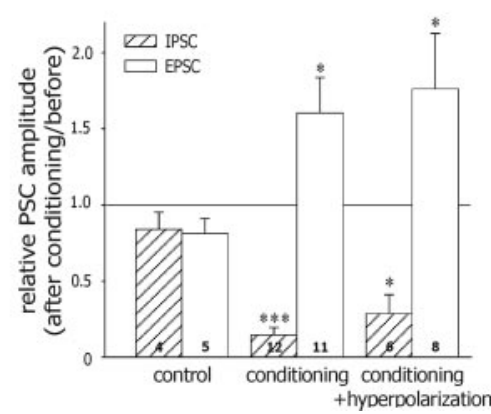

quency) and postsynaptic (increase in mEPSC size) components of the EPSC, resulting in an increased efficacy of the synapse.

\section{Responses to paired stimulation}

Another estimate of the possible locus of change is the response to a paired-pulse stimulation paradigm in which two action potentials are evoked in the presynaptic neuron with a short interspike interval. Under our testing conditions measured at $30 \mathrm{~ms}$ interpulse interval, the second response in a pair of EPSCs was depressed relative to the first one, with a paired pulse ratio (PPR) of $0.72 \pm 0.22$. After conditioning, in addition to the increased EPSC amplitude shown before (LTPe), the EPSC PPR was increased significantly to $1.37 \pm$ 0.34 (Fig. $6 A, B)(p<0.05)$. This indicates that the change in EPSC is likely to be attributable to an increase in the release probability of the excitatory transmitter at a synapse with initially low probability of release that is not saturated by the conditioning. This increase in PPR is not likely to be caused by attenuation of the efficacy of an inhibitory synapse that is activated in parallel with the postsynaptic EPSC because saclofen, which blocks LTDi, does not affect LTPe (see below).

The inhibitory PPR was not affected by conditioning and remained unchanged at $0.92 \pm 0.16$ and $0.93 \pm 0.16$ before and after conditioning, respectively, despite a marked decrease in the size of the initial evoked response to a single stimulation (Fig. 6C,D) $(p>0.98)$.

ring in LTPe and LTDi. We recorded mEPSCs from the same sets of neurons before and after conditioning, shifting from TTX solution to CM and then TTX solution again. Because of technical limitations, mIPSCs were recorded from separate populations of neurons before and after conditioning. The averaged mEPSC amplitude was increased significantly from $20.09 \pm 1.58$ to $22.446 \pm$ $1.65 \mathrm{pA}$ after conditioning (Fig. $5 B$ ) (paired $t$ test, $p<0.05$ ). The number of mEPSCs per minute was increased dramatically from $70.46 \pm 15.07$ to $166.36 \pm 36.06$ after CM (Fig. $5 C)(p<0.001)$. The mEPSC total rise time was increased from $5.10 \pm 0.19$ to $5.58 \pm 0.17 \mathrm{~ms}$ after conditioning (Fig. $5 D)(p<0.05)$. Decay times were not affected by the conditioning (Fig. $5 E)(p>0.23)$. By comparison, mIPSC parameters were not affected at all by conditioning. mIPSC amplitude remained constant, at $19.27 \pm$ $2.23 \mathrm{pA}$ before and $20.46 \pm 1.83 \mathrm{pA}$ after conditioning (Fig. $5 G$ ) $(p>0.68)$. The number of mIPSC events per minute was $12.01 \pm 2.45$ before and $11.36 \pm 2.37$ after conditioning, respectively (Fig. $5 H)(p>0.84)$. Total rise time and decay times remained unchanged as well after conditioning (Fig. 5I,J) $(p>$ 0.52 and 0.12 , respectively). These results indicate that, although conditioning caused a persistent reduction in evoked IPSCs (LTDi), it does not affect properties of individual spontaneous mIPSCs or the postsynaptic response to synaptic release of GABA. Conversely, conditioning causes a persistent increase in EPSC by affecting both presynaptic (increase in mEPSC fre-

LTDi is probably not mediated by either a change in spontaneous individual inhibitory synaptic currents or a change in release probability at the presynaptic GABAergic terminals. Postsynaptic GABA receptors were not affected as well, because there was no consistent effect of conditioning on reactivity to pulse application of GABA (data not shown) or on the size of mIPSCs. We then tested whether the presynaptic GABAergic neuron action potential is affected by the conditioning. To this end, we examined several properties of the spike, including its threshold $(-27.25 \pm 4.98 \mathrm{mV}$ before and $-30.11 \pm 5.15 \mathrm{mV}$ after conditioning; $p>0.69$ ), half-duration (1.69 \pm 0.21 and $1.91 \pm 0.49 \mathrm{~ms} ; p>0.68)$, amplitude $(89.38 \pm 9.99$ and $91.78 \pm$ $8.59 \mathrm{mV} ; p>0.85)$, and rise time ( $1.9 \pm 0.31$ and $1.36 \pm 0.18 \mathrm{~ms}$; $p>0.61)$. None of these parameters was affected by conditioning, indicating that properties of the spike, including conduction velocity of the inhibitory axon, were not affected. Therefore, the locus of change is likely to be downstream to the presynaptic action potential and upstream to the release site at the synapse.

\section{$\mathrm{GABA}_{\mathrm{B}}$ receptor mediation}

In an additional effort to identify the locus in which LTDi is manifested, we examined the role of the $\mathrm{GABA}_{\mathrm{B}}$ presynaptic receptor, known to be involved in suppression of inhibition (Mott and Lewis, 1991; Wagner and Alger, 1995; Than and Szabo, 2002). The presynaptic $\mathrm{GABA}_{\mathrm{B}}$ receptor serves as an autorecep- 

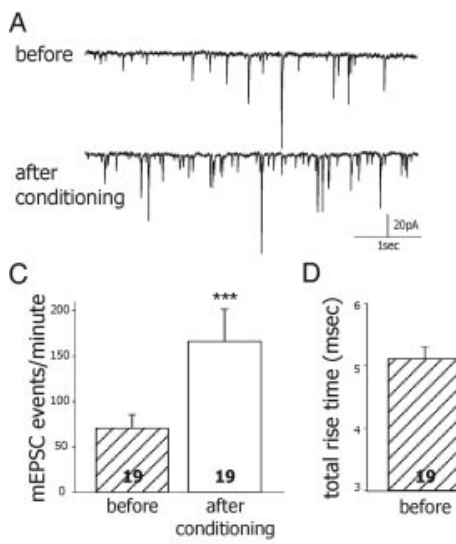

D
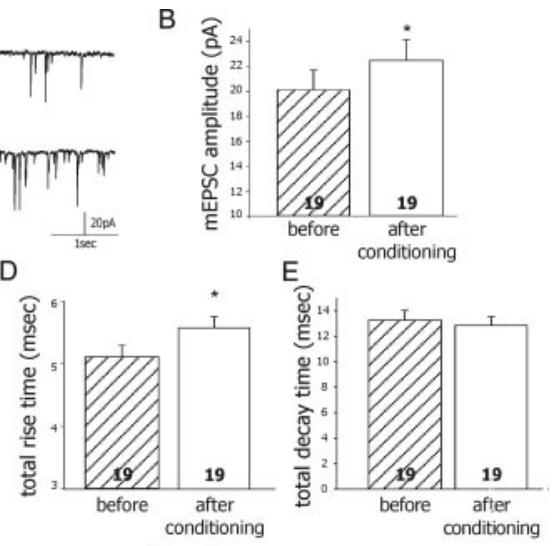

$\mathrm{F}$

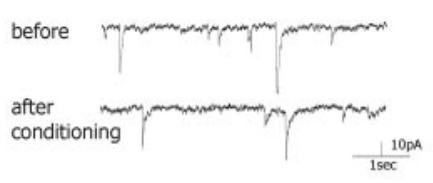

G

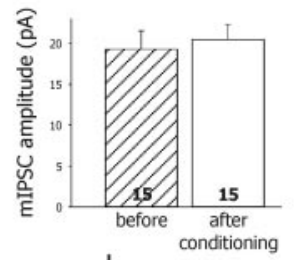

$\mathrm{H}$
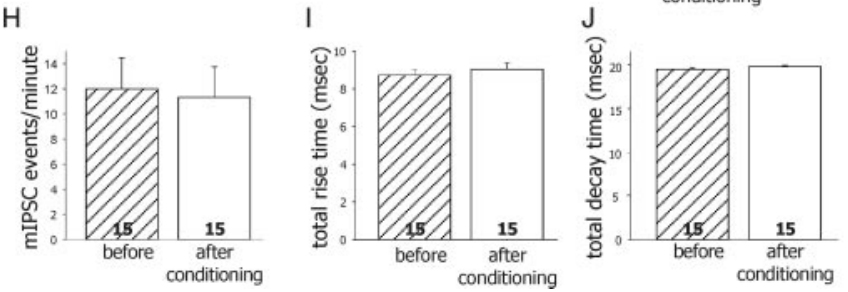

Figure 5. Spontaneous transmitter release after conditioning. $\boldsymbol{A}$, Voltage-clamp whole-cell recordings of $\mathrm{mEPSC}$ in presence of TTX, from same neuron before (top) and after (bottom) conditioning at $-60 \mathrm{mV}$. $\boldsymbol{B}$, Average $\mathrm{mEPSC}$ amplitudes before and after conditioning, significantly elevated from $20.09 \pm 1.58$ to $22.446 \pm 1.65 \mathrm{pA}$. C, Averaged number of mEPSCs per minute showing a significant increase from $70.46 \pm 15.07$ to $166.36 \pm 36.06$. D , Averaged $\mathrm{mEPSC}$ rise time, which changed from $5.10 \pm 0.19$ to $5.58 \pm 0.17 \mathrm{~ms}$. $E$, Averaged decay time did not change after conditioning. $\boldsymbol{F}-\boldsymbol{J}, \mathrm{mIPSC}$. $\boldsymbol{F}$, Voltage-clamp whole-cell recordings of mIPSCs from neurons before (top) and after (bottom) conditioning at $-60 \mathrm{mV}$. G, Averaged mIPSC amplitude before and after conditioning. $\boldsymbol{H}$, Averaged number of mIPSCS recorded per minute. Average mIPSC rise time $(\boldsymbol{I})$ and averaged decay time $(\boldsymbol{J})$ before and after conditioning. The units are averages of the average statistic per neuron.

tor, which, during GABA binding, leads to its decreased release through a mechanism involving altered $\mathrm{Ca}^{2+}$ and $\mathrm{K}$ conductances (Gahwiler and Brown, 1985; Misgeld et al., 1994, 1995). When $100 \mu \mathrm{M}$ of the $\mathrm{GABA}_{\mathrm{B}}$ receptor antagonist saclofen was applied to the CM (saclofen-CM), LTDi was blocked, and the relative evoked IPSC amplitude remained similar to control, at $0.92 \pm 0.03$ relative to baseline value $(p>0.46$ compared with control) and significantly different from normal conditioning experiments (Fig. $7 A, B$ ). Hence, the conditioning, which caused an increased activity of interneurons, enhanced GABA release, and, subsequently, a prolonged increase in activation of the $\mathrm{GABA}_{\mathrm{B}}$ receptor, leading to a decreased efficacy of invasion of the presynaptic GABAergic terminal, is required in the induction of LTDi. Because saclofen has been suggested to work as a partial $\mathrm{GABA}_{\mathrm{B}}$ receptor agonist (Caddick et al., 1995), we also used CGP55845 (3 $\mu \mathrm{M})$, taken to be a more potent antagonist (Davies et al., 1993). CGP55845-CM also blocked LTDi, and the relative evoked IPSC amplitude remained at $0.77 \pm 0.14$ relative to baseline values ( $p>0.56$ compared with control). To identify the critical time required for $\mathrm{GABA}_{\mathrm{B}}$ activation needed to produce LTDi, we added $100 \mu \mathrm{M}$ saclofen along with the normal recording medium after washout of normal CM. Under these
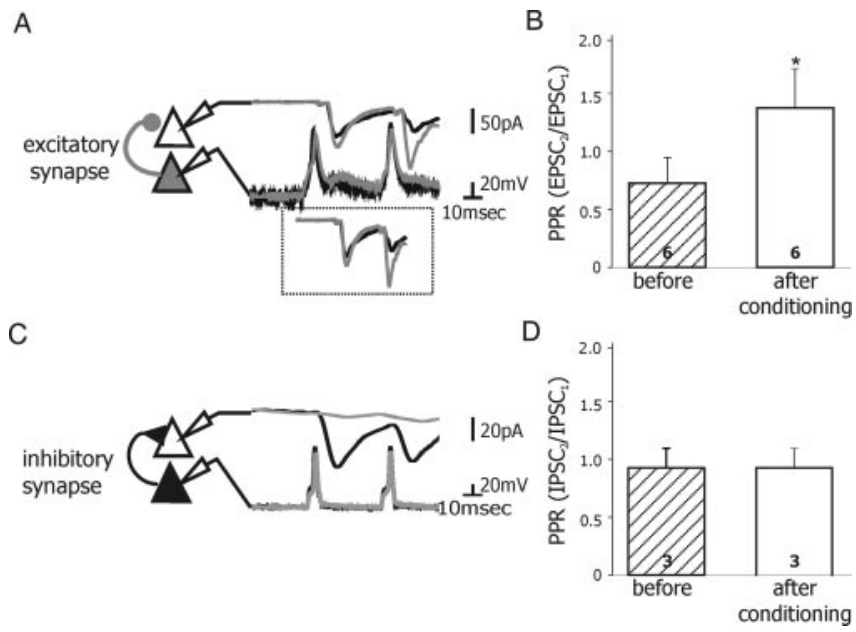

Figure 6. Conditioning increases paired-pulse potentiation of excitatory but not of inhibitory transmission. $A$, Example of paired-pulse paradigm with an interstimulus interval of $30 \mathrm{~ms}$ of one excitatory synapse before (black traces) and after (gray traces) conditioning showing increased EPSC amplitude and PPR after conditioning. Asterisk indicates the evoked EPSC measured. Inset is normalized to first peak in control trace, showing increased current evoked by the second pulse. $\boldsymbol{B}$, The averaged PPR increased from $0.72 \pm 0.22$ before to $1.37 \pm 0.34$ after conditioning. C, Example of PPR with an interstimulus interval of $30 \mathrm{~ms}$ of one inhibitory synapse before (black traces) and after (gray traces) conditioning showing decreased IPSC amplitude after conditioning but no change in PPR. D, Averaged PPR of IPSCs before $(0.92 \pm 0.16)$ and after $(0.93 \pm 0.16)$ conditioning.

testing conditions, the relative amplitude of evoked IPSC was decreased to $0.13 \pm 0.06$, as in the conditioning experiments (Fig. $7 B)(p>0.86$ compared with conditioning). These results indicate that saclofen is effective only when applied during but not after the conditioning interval, and, once the $\mathrm{GABA}_{\mathrm{B}}$ receptor is activated to reduce GABA release, it becomes insensitive to saclofen.

It has been suggested that the $\mathrm{GABA}_{\mathrm{B}}$ receptor plays a facilitative role in the induction of LTP (Mott and Lewis, 1991). We therefore tested the effects of saclofen on LTPe. After application of saclofen-CM, LTPe occurred, and the relative evoked EPSC amplitude increased to $1.58 \pm 0.21$ relative to baseline values $(p<0.01$ compared with control), similar to normal conditioning experiments (Fig. 7C,D) $(p>0.81)$.

The time course of the effect of saclofen on blockade of LTDi, shown in Figure 7E, indicates that the relative IPSC amplitude remains constant throughout the washin and washout of the saclofen-CM. It is interesting to note that the changes in spontaneous network activity were similar to those found in normal conditioning experiments, and the network activity became more robust and synchronized (Fig. $7 F$ ).

These experiments indicate that the enhanced postsynaptic activation of NMDA receptors leads to enhanced presynaptic GABAergic activity, which mediates activation of the presynaptic $\mathrm{GABA}_{\mathrm{B}}$ receptors, resulting in a long-lasting suppression of inhibition. It should be noted that the potential presence and activation of presynaptic NMDA receptors may also be involved, and their role vis-à-vis GABAergic terminals cannot be ignored (see Discussion).

Can the increase in GABAergic activity in and of itself produce the long-lasting reduction in inhibition? To address this possibility, we evoked trains of action potentials in the GABAergic neuron and measured the subsequent IPSCs in the postsynaptic neuron. No long-lasting change in IPSCs was found in four neurons tested (Fig. 8), indicating that the activity of the GABAergic 

conditioning
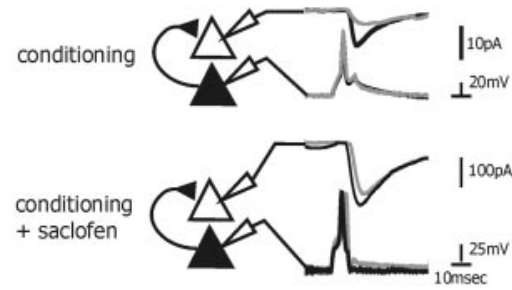

B

C

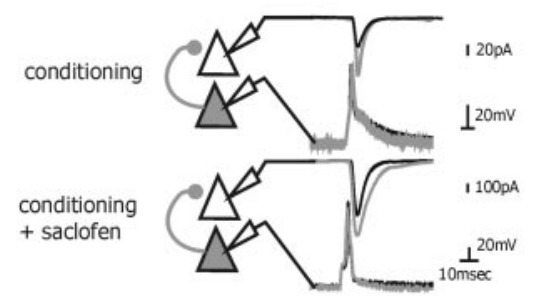

E

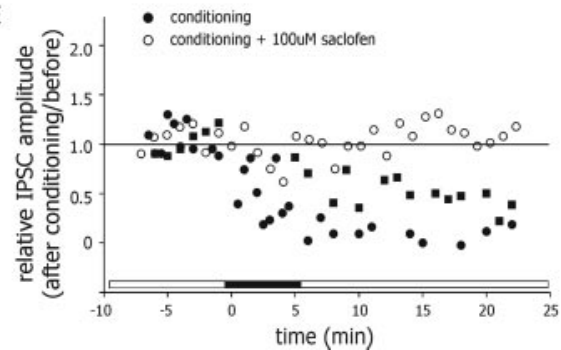

Figure 7. LTDi is mediated through activation of a $G_{A B A}$ receptor. $A$, Top, Example of whole-cell recordings of an inhibitory synapse before (black traces) and after (gray traces) conditioning. Bottom, Same as in the top trace, but recorded after saclofenCM, showing a blockade of LTDi. B, Summary of all experiments with saclofen and CGP55845. When the saclofen was applied at the time of the CM, the IPSC amplitude remained at $0.92 \pm 0.03$, similar to control experiments, whereas when saclofen was applied directly after washin and washout of the CM, it did not reverse the LTDi, and IPSC amplitude plummeted to $0.13 \pm 0.06$. When CGP55845-CM was used, the relative IPSC amplitude remained at $0.73 \pm 0.14$, similar to control. C, $\boldsymbol{D}$, Same as in $\boldsymbol{A}$ and $\boldsymbol{B}$ but for an excitatory synapse. Saclofen-CM did not inhibit induction of LTPe, and relative evoked EPSC amplitude increased to $1.58 \pm$ 0.21 after conditioning, relative to baseline. $\boldsymbol{E}$, Time course of relative evoked inhibitory currents with saclofen-CM versus $C M$ alone (open and filled circles, respectively). Black bar at 0 min on the abscissa indicates a 5 min wash in of the $C M$ to activate synaptic NMDA receptors or of saclofen-CM. F, Spontaneous activity of two neurons recorded in current-clamp (top) and voltageclamp (bottom) configuration before and after saclofen-CM. The activity becomes more robust and synchronized, similar to the modifications in spontaneous activity seen when conditioning was applied alone, as shown in Figure 1.

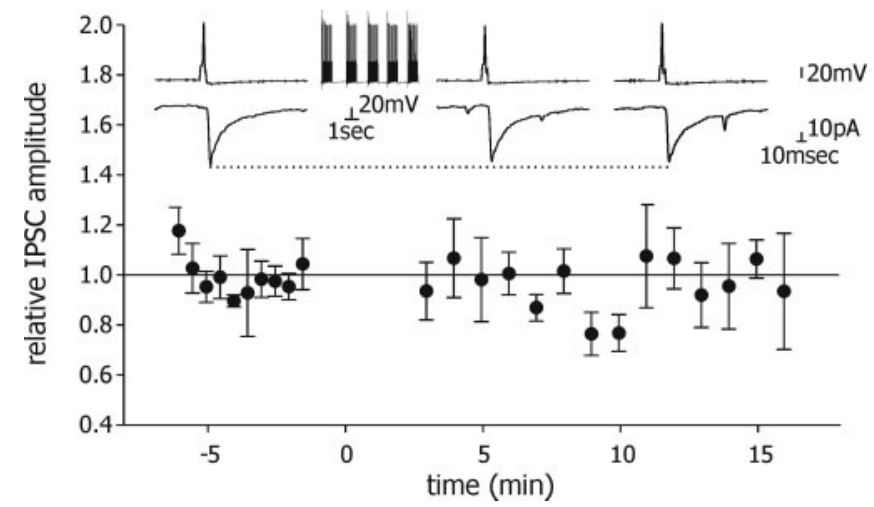

Figure 8. Tetanic stimulation of GABAergic neuron does not produce LTDi. Graph showing evoked IPSC before and after five consecutive 1-s-long pulses of $50 \mathrm{~Hz}$ to the presynaptic GABAergic neuron, showing no LTDi. Insets are typical examples of pairs of evoked GABAergic neuron action potentials and their IPSC s before and after stimulation of the presynaptic neuron. Also shown are trains of presynaptic action potential discharges $(n=4)$. neuron by itself does not cause a lasting change in IPSC. Instead, a coactivation of the presynaptic and postsynaptic neuron or simultaneous activation of networks of excitatory and inhibitory neurons is likely to cause this long-lasting change in inhibition.

\section{cAMP}

Activation of the presynaptic $\mathrm{GABA}_{\mathrm{B}}$ receptor involves the cAMP cascade (Knight and Bowery, 1996). In addition, this second-messenger system is involved in induction and maintenance of LTP (Frey et al., 1993; Huang et al., 1994; Blitzer et al., 1995). We examined the role of cAMP in LTDi and LTPe using Rp-cAMPs, a diastereoisomer antagonist of cAMP. When $100 \mu \mathrm{M}$ Rp-cAMPs was applied along with the conditioning medium (Rp-cAMPs$\mathrm{CM}$ ), no significant change was seen in evoked PSC amplitudes. Relative EPSC amplitudes remained at $1.01 \pm 0.13$, and IPSC amplitudes remained unchanged as well, at $0.81 \pm 0.18$ (Fig. $9 A-C)(p>0.35$ and 0.94 compared with control, respectively). To further determine the locus of cAMP action necessary for LTPe and LTDi, Rp-cAMPs was added to the intracellular solution at a final concentration of $100 \mu \mathrm{M}$ and then introduced into one of the two neurons in the dual-recording configuration. The Rp-cAMPs-loaded neuron could therefore be either a presynaptic or a postsynaptic pyramidal or interneuron. When a presynaptic pyramidal neuron was loaded with $\mathrm{Rp}$ cAMPs, the relative evoked EPSC amplitude was increased to $2.07 \pm 0.52$ after conditioning, and LTPe was induced (Fig. 9A,C) $(n=8$; $p<0.05)$. Conversely, when a postsynaptic neuron was loaded with Rp-cAMPs, LTPe was not induced, and the evoked EPSC remained constant as in control recordings, at $0.81 \pm 0.21$ after conditioning, relative to baseline values (Fig. 9A,C) $(n=7 ; p>0.99)$. Next, when a presynaptic GABAergic interneuron was loaded with RpCAMPs, the evoked IPSC remained unchanged, and LTDi was blocked. Evoked IPSCs remained unchanged, at $0.69 \pm 0.16$ (Fig. 9A,C) $(n=5 ; p>0.49)$. However, when a postsynaptic neuron was loaded with Rp-cAMPs, LTDi was induced, and the evoked IPSC plummeted to $0.16 \pm 0.05$ after conditioning, relative to baseline values (Fig. $9 A, C)(n=6$; $p<0.005)$. These results indicate that cAMP action in the postsynaptic neuron, and in the presynaptic neuron, are essential in LTPe and LTDi, respectively.

Not surprisingly, applying the cAMP activator forskolin (50 $\mu \mathrm{M})$ in either the presynaptic or postsynaptic neuron leads to LTPe and LTDi, as the case may be (Fig. 9C).

The modifications of spontaneous activity in the hippocampal network seen after conditioning also appear to be dependent on activation of cAMP, because Rp-cAMPs-CM blocked synchronized activity and network modifications (Fig. 9D). 


\section{Nitric oxide}

The retrograde messenger nitric oxide (NO) has been implicated in the production of LTD in the cerebellum and hippocampus and LTP in the hippocampus and cerebral cortex (Izumi and Zorumski, 1993; Nowicky and Bindman, 1993; Zorumski and Izumi, 1998; Stanton et al., 2003). To determine the role of NO in LTPe and LTDi, the NO synthase inhibitor L-NNA was diluted in the CM to a final concentration of $100 \mu \mathrm{M}$ (L-NNA-CM). Under these conditions, both LTPe and LTDi were induced, as in normal conditioning experiments. Evoked EPSC amplitudes were increased to $2.09 \pm 0.14$ relative to baseline values (Fig. $10 A, C)(n=2$; $p<0.001$ compared with control). Evoked IPSC amplitudes were decreased to $0.26 \pm 0.10$ relative to baseline values (Fig. $10 B, C)(n=6 ; p<0.005)$. These results indicate that, unlike in other types of hippocampal plasticities, NO does not play a role in the NMDA-dependent plasticities demonstrated here. This however does not negate the possibility that, within the vicinity of these activated pathways, other nonactivated synapses also become modified. The LTPe or LTDi generated here at one synaptic input to a hippocampal neuron may possibly spread to adjacent synapses on a different postsynaptic neuron in physical proximity (Bonhoeffer et al., 1989; Engert and Bonhoeffer, 1997).

\section{Spike-timing-dependent plasticity}

STDP has been studied extensively over the past decade, and it is now evident that, in this type of plasticity, backpropagating action potentials, when initiated at the appropriate time during repetitive synaptic activation, are effective in inducing persistent synaptic modification (Markram et al., 1997; Bi and Poo, 1999). We studied the relationships between STDP and network plasticity in the hippocampal cultures, trying to determine whether the networkinduced LTPe is a unique phenomenon. If so, we would then expect both types of induction protocols to evoke potentiation independent of each other. To study this, we recorded from pairs of neurons and used an STDP protocol described previously (Markram et al., 1997). Because it has been suggested that target neuron-specific mechanisms are involved in the induction of synaptic modifications ( $\mathrm{Bi}$ and Poo, 1999), care was taken to identify the postsynaptic neuron as glutamatergic or GABAergic, which could only be possible if it sent a reciprocal synapse onto the presynaptic neuron. Bi and Poo (1999) also reported that glutamatergic synapses made onto GABAergic neurons were not amenable to potentiation by the correlated presynaptic and postsynaptic activity. Neurons that made no reciprocal synapse were also used in this study.

STDP with a pre-postsynaptic delay of $5 \mathrm{~ms}$ induced LTP reproducibly in the hippocampal cultures (Fig. 11A). Such was the case whether the postsynaptic neuron sent a reciprocal exci-
B
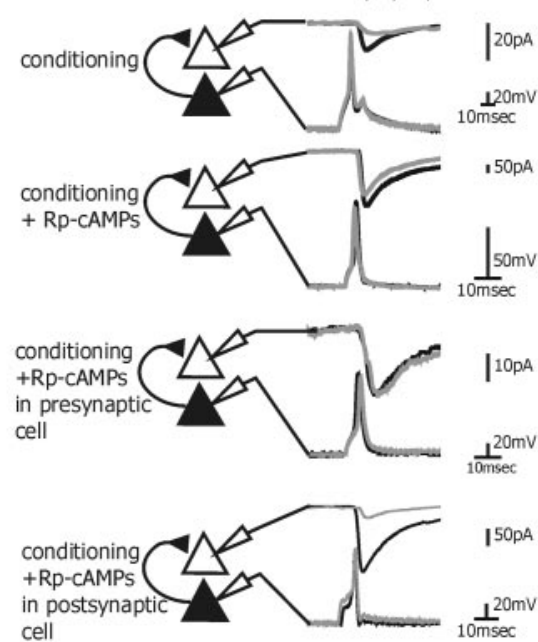

cell

D

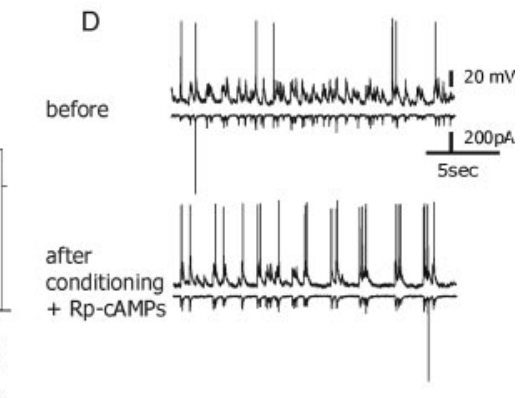

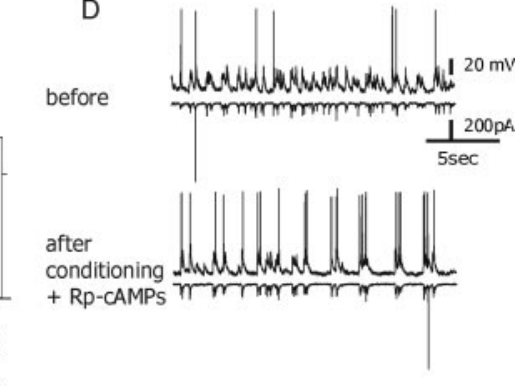

Figure 9. LTPe and LTDi are CAMP dependent. $\boldsymbol{A}$, Top to bottom, Examples of an excitatory synapse before (black traces) and

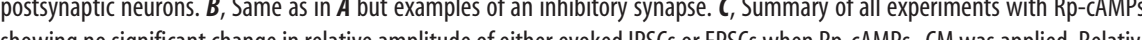
showing no significant change in relative amplitude of either evoked IPSCs or EPSCs when Rp-CAMPs-CM was applied. Relative s. When occur (evoked IPSC amplitude remained as in control, at $0.69 \pm 0.16$ ). When Rp-cAMPs was loaded in the postsynaptic neuron, LTPe was not induced and the evoked EPSC remained constant at $0.81 \pm 0.21$ after conditioning, but LTDi was induced and the evoked IPSC plummeted to $0.16 \pm 0.05$. Forskolin added to the presynaptic neuron did not affect LTDi or LTPe, and relative 列 $0.24 \pm 0.17$ and $1.28 \pm 0.20$, as in conditioning experiments. Forskolin added to the postsynaptic neuron also activity recorded from two adjacent neurons in current-clamp (top traces) and voltage-clamp (bottom traces) configuration before (top) and after (bottom) Rp-cAMPs-CM showing no change in spontaneous activity, unlike when CM was applied alone.

tatory synapse back onto the presynaptic neuron or none at all. In a separate set of experiments, potentiation was first induced by the STDP protocol, followed by induction of network-driven NMDA-dependent plasticity, as in the conditioning experiments, and the evoked EPSC was reexamined. In three of four experiments, the conditioning led to an additional significant potentiation of the evoked EPSC (LTPe) (Fig. $11 B$ ). Interestingly, when the postsynaptic neuron was verified as inhibitory, i.e., sent an inhibitory synapse onto the presynaptic neuron, the same STDP protocol evoked a subtle LTD (Fig. 11C), unlike what was reported previously (Bi and Poo, 1999). In two of three experiments, a prominent depression of the evoked EPSC was then reversed by exposure to the network conditioning medium (Fig. $11 D)$, and, as shown, the EPSC was potentiated to beyond baseline levels.

\section{Discussion}

The present study analyzes a robust change in connectivity among neurons in dissociated cultures of the rat hippocampus 
A
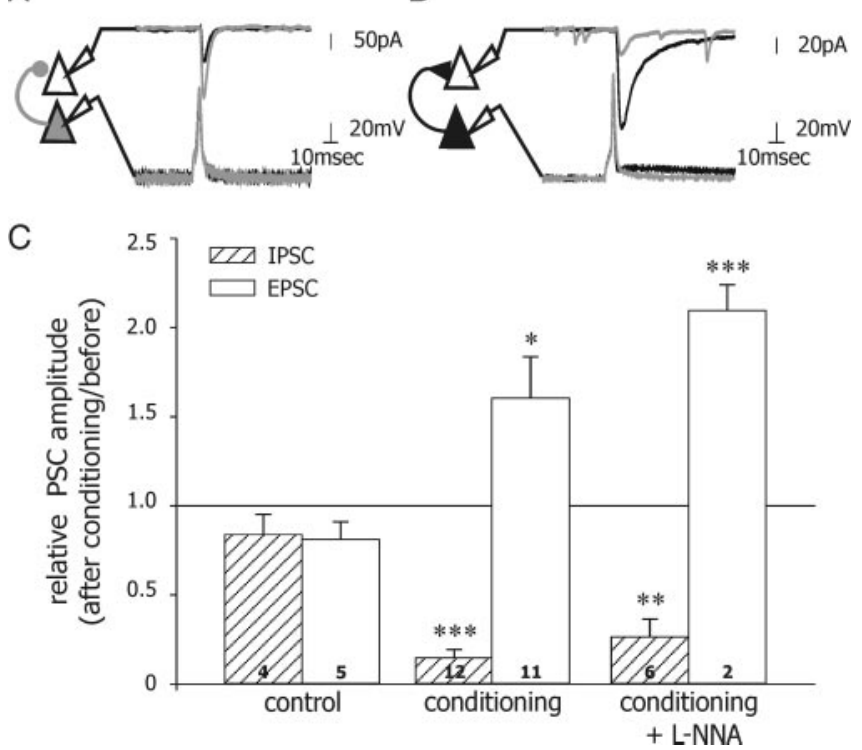

Figure 10. Blockade of NO synthesis does not affect LTPe or LTDi. $A$, Example of an excitatory synapse before (black traces) and after (gray traces) L-NNA was applied at time of conditioning, showing LTPe. $\boldsymbol{B}$, Same as in $\boldsymbol{A}$ but examples of an inhibitory synapse, showing LTDi. $\boldsymbol{C}$, Summary of all experiments with L-NNA showing typical LTPe and LTDi when L-NNA-CM was applied. Relative evoked EPSC amplitudes were increased to $2.09 \pm 0.14$ relative to baseline values. Relative evoked IPSC amplitudes were decreased to $0.26 \pm 0.10$ relative to baseline values.

after a brief exposure to a conditioning medium that favors activation of synaptic NMDA receptors. As shown before, chronic blockade of NMDA receptor activity by growing the culture in the presence of an NMDA antagonist, APV, causes an upregulation of the NMDA receptor such that, when the blockade is transiently removed, there is an enhanced activation of the receptor (Goldin et al., 2001; Lu et al., 2001). Here we show that the transient activation of the NMDA receptor enhances network activity in the culture and causes synchronization among adjacent neurons, resulting in a long-lasting strengthening of excitatory connections and weakening of inhibitory connections among neurons.

The simplicity of the dissociated culture allows us to address several issues related to synaptic plasticity. The nature of the stimulation protocol, which allows for a maximal number of synapses to be activated, has advantages over the commonly used electrical stimulation of specific pathways in studying morphological and molecular bases of synaptic plasticity. More specifically, our test situation extends the ability to examine parameters related to synaptic plasticity, including the locus of change, as well as specific excitatory or inhibitory long-term synaptic changes.

A long-standing issue in synaptic plasticity is related to the loci of induction and maintenance of changes associated with LTP. A large number of studies indicate that the locus of induction of LTP in most synapses studied is postsynaptic and involves a rise of intracellular calcium concentration (Lynch et al., 1983), whereas the maintenance can be presynaptic, involving a change in release properties (Bekkers and Stevens, 1990; Malinow and Tsien, 1990; Kullmann and Siegelbaum, 1995; Malenka and Nicoll, 1999; Nicoll and Malenka, 1999). It is further suggested that the switch between the postsynaptic and the presynaptic loci is mediated by a retrograde messenger (Williams et al., 1989). Others suggest that the locus of long-term change is postsynaptic and involves insertion of glutamate receptors into an existing
NMDA receptor-containing but functionally silent synapse (Malenka and Nicoll, 1999; Malinow and Malenka, 2002; Bredt and Nicoll, 2003). Although the wealth of experimental evidence favoring a postsynaptic location of LTP is overwhelming, it is likely that, in the same excitatory pathway, some synapses undergo changes in both presynaptic and postsynaptic locations (Emptage et al., 2003, Voronin et al., 2004).

In the cultured neurons studied herein, the locus of induction of LTDi is likely to be mainly presynaptic in that it does not require either a change in postsynaptic $\mathrm{Ca}^{2+}$ concentration or postsynaptic depolarization, because LTDi occurred when the postsynaptic neuron was voltage clamped throughout the entirety of the conditioning experiments, and, thus, no depolarization of the postsynaptic membrane was needed to produce the long-term change. Still, the presynaptic terminal is probably not the sole site of induction of the change, because a tetanic activation of the GABAergic neuron by itself did not mimic the longlasting suppression of inhibition seen when the network was activated, indicating the possible need for coactivation of other neurons together with the presynaptic GABAergic neuron.

The locus of expression of LTPe is likely to be primarily presynaptic, noted by the increase in mEPSC frequency. However, a small increase in mEPSC amplitude indicates an additional postsynaptic location. Furthermore, the enhanced presynaptic activity may result in the conversion of a silent into an active synapse. In support of this, we have seen a rapid influx of glutamate receptors into silent postsynaptic sites (our unpublished observations), as well as a formation of new dendritic spines after exposure to the conditioning medium (Goldin et al., 2001).

Nonetheless, there are distinct differences between LTPe and LTDi sufficient to indicate that different mechanisms are associated with the two types of long-term synaptic changes. LTPe but not LTDi was associated with an increase in paired-pulse response (see below). LTPe was dependent on activation of postsynaptic but not presynaptic cAMP, and the opposite is true for LTDi. LTPe was associated with a change in mEPSCs, unlike LTDi. LTDi could be blocked by drugs that do not affect LTPe and vice versa. These results indicate that the two processes are parallel but not interdependent.

In previous studies, the lack of change in paired-pulse response was taken to indicate a postsynaptic locus of LTP, whereas a reduction in paired-pulse potentiation indicated a presynaptic increase in release probability in response to the first stimulus with a subsequent reduction in efficacy of the second response (Schulz et al., 1994; Kleschevnikov et al., 1997). This interpretation, which originated in experiments on the neuromuscular junction (Katz and Miledi, 1968), is supported by extracellular recording in hippocampal slices (Schulz et al., 1994), a situation in which the stimulation is likely to activate both excitatory and inhibitory pathways, and the end product may be confounded by parallel changes in both excitation and inhibition, as is the case in our rather simple system. The current results, conducted on single connections between neurons, are likely to reflect true changes in release probability between the two neurons, but it can also be affected by a reduction in activity of a parallel inhibitory synapse. If indeed the connection between neurons in culture consists of synapses with low release probability (Slutsky et al., 2004), there is no a priori reason to believe that an increase in release probability to the first stimulus will not result in an additional increase in release, after accumulation of calcium, in response to the second stimulation (Schulz et al., 1994; Santschi and Stanton, 2003).

Another issue concerns the modulation of inhibition in LTP. 
Early studies could clearly distinguish between direct enhancement of the EPSP and a separate indirect effect of a change in the coupling of dendritic EPSPs to somatic action potential generation (Yamamoto and Chujo, 1978; Abraham et al., 1987). However, it has been debated whether interneurons can undergo long-term plastic changes at all (Griffith et al., 1986). At any rate, whereas a long-lasting reduction of inhibition that accompanies LTP has been demonstrated in hippocampal slices (Lu et al., 2000), measurement of such a longterm reduction in efficacy of individual inhibitory synapses has not been demonstrated (Mott and Lewis, 1991; Wang and Stelzer, 1996).

The reduction in evoked IPSC (LTDi) reported is unique indeed in that it comprises a very large and persistent change in inhibitory synaptic currents. This change is not likely to be mediated by a postsynaptic desensitization of the GABAergic receptor, because the mIPSC amplitude was not affected by the conditioning, as neither were responses to GABA puff applications (data not shown). Also, it is not likely that the GABAergic neuron changed its intrinsic properties after conditioning, because the latency, threshold, and other properties of the GABAergic neuron action potentials remained stable after conditioning. Likewise, the latency from the action potential to the IPSC was not changed, indicating that conduction velocity in the GABAergic axons remained stable after conditioning. One could hypothesize that the increased firing rate of the GABAergic neurons induced during conditioning in and of itself could cause fatigue of the GABA release machinery, leading to LTDi; however, stimulation of the GABAergic neurons at high frequencies similar to those seen during conditioning did not cause a decrease in evoked IPSCs. This indicates that a conjunction of presynaptic GABAergic activity with NMDA receptor activation produced by enhanced network activity caused this long-lasting decrease in efficacy of transmission at the GABAergic synapse. Whether this is a direct effect of a presynaptic NMDA receptor residing on GABAergic terminals or is mediated by another, yet unknown, interneuron remains to be determined.

Other evidence for changes in efficacy of GABAergic synapses have been reported, including Hebbian LTP (Lamsa et al., 2005), as well as depression, as in the case of depolarization-induced suppression of inhibition (DSI) (Ohno-Shosaku et al., 1998; Ohno-Shosaku et al., 2000). However, DSI is much shorter lasting and involves changes in postsynaptic $\mathrm{Ca}^{2+}$ concentration. One other study that reported a parallel change in EPSPs and IPSPs was conducted on hippocampal slices and demonstrated a long-lasting decrease in what is most likely a feedforward IPSP that is produced by stimulation of the Schaffer collateral pathway (Lu et al., 2000). Our study demonstrates that the change is not likely to take place at the GABAergic somata, axon, or the postsynaptic receptor because no change in mIPSCs has been detected, but rather in the linkage between the axonal action

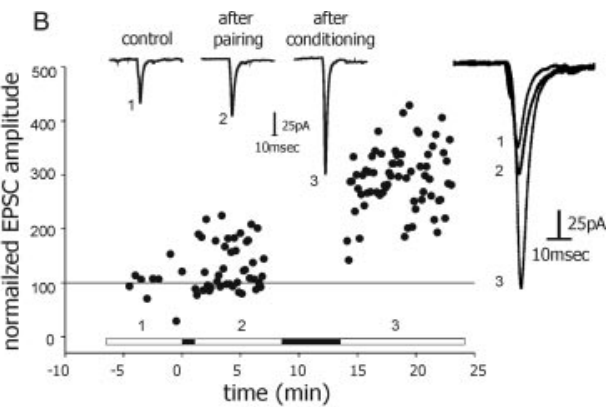

D
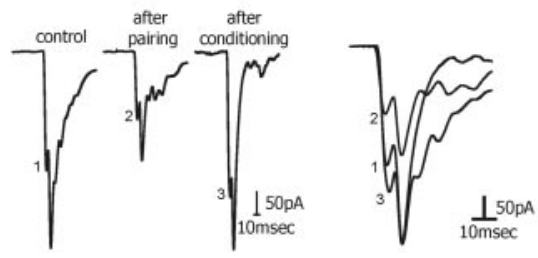

Figure 11. LTPe and LTDi are independent of STDP. A, Summary of all pairing experiments when the presynaptic and postsyn( 列 . On the right are the superimposed blown-up traces.

potential and the release mechanism, and involves activation of the $\mathrm{GABA}_{\mathrm{B}}$ receptor. Whether a retrograde messenger other then $\mathrm{NO}$ is responsible for this long-lasting change in efficacy of the GABAergic synapse is not known as yet, but several candidates for such an action exists (Ohno-Shosaku et al., 2000; Ohno-Shosaku et al., 2002; Yanovsky et al., 2003). In any case, the retrograde effect is likely to involve a $\mathrm{GABA}_{\mathrm{B}}$ receptor.

The main advantage of the NMDA-mediated chemical LTPe and LTDi is that it enhances activity of a large proportion of the synapses within the network. Thus, a morphological change associated with the functional plasticity is likely to be easier to detect than in the case of a localized stimulation. Indeed, in previous studies with the same type of synaptic activation, a pronounced increase in dendritic spine density has been detected (Goldin et al., 2001) that was larger than changes seen after electrically stimulated pathways (Engert and Bonhoeffer, 1999). Interestingly, the morphological changes reported in dendritic spine density took place long after $(30-60 \mathrm{~min})$ the electrophysiological change, indicating that the morphological changes are subsequent to the network and synaptic electrophysiological changes.

In conclusion, this work articulately defines LTPe and LTDi occurring simultaneously, but independently, after conditioning of NMDA receptor activity. These studies indicate for the first time that network plasticity involves equal and opposite affects on inhibitory and excitatory neurotransmission and as such should have important implications to studies on long-term plasticity. 


\section{References}

Abraham WC, Gustafsson B, Wigstrom H (1987) Long-term potentiation involves enhanced synaptic excitation relative to synaptic inhibition in guinea-pig hippocampus. J Physiol (Lond) 394:367-380.

Bekkers JM, Stevens CF (1990) Presynaptic mechanism for long-term potentiation in the hippocampus. Nature 346:724-729.

Bi G, Poo M (1999) Distributed synaptic modification in neural networks induced by patterned stimulation. Nature 401:792-796.

Bliss TV, Lomo T (1973) Long-lasting potentiation of synaptic transmission in the dentate area of the anaesthetized rabbit following stimulation of the perforant path. J Physiol (Lond) 232:331-356.

Blitzer RD, Wong T, Nouranifar R, Iyengar R, Landau EM (1995) Postsynaptic cAMP pathway gates early LTP in hippocampal CA1 region. Neuron 15:1403-1414.

Bonhoeffer T, Staiger V, Aertsen A (1989) Synaptic plasticity in rat hippocampal slice cultures: local "Hebbian" conjunction of pre- and postsynaptic stimulation leads to distributed synaptic enhancement. Proc Natl Acad Sci USA 86:8113-8117.

Bredt DS, Nicoll RA (2003) AMPA receptor trafficking at excitatory synapses. Neuron 40:361-379.

Caddick SJ, Stanford IM, Chad JE (1995) 2-Hydroxy-saclofen causes a phaclofen-reversible reduction in population spike amplitude in the rat hippocampal slice. Eur J Pharmacol 274:41-46.

Davies CH, Pozza MF, Collingridge GL (1993) CGP 55845A: a potent antagonist of GABAB receptors in the CA1 region of rat hippocampus. Neuropharmacology 32:1071-1073.

Emptage NJ, Reid CA, Fine A, Bliss TV (2003) Optical quantal analysis reveals a presynaptic component of LTP at hippocampal Schafferassociational synapses. Neuron 38:797-804.

Engert F, Bonhoeffer T (1997) Synapse specificity of long-term potentiation breaks down at short distances. Nature 388:279-284.

Engert F, Bonhoeffer T (1999) Dendritic spine changes associated with hippocampal long-term synaptic plasticity. Nature 399:66-70.

Frey U, Huang YY, Kandel ER (1993) Effects of cAMP simulate a late stage of LTP in hippocampal CA1 neurons. Science 260:1661-1664.

Fujii S, Sasaki H, Mikoshiba K, Kuroda Y, Yamazaki Y, Mostafa Taufiq A, Kato H (2004) A chemical LTP induced by co-activation of metabotropic and $N$-methyl-D-aspartate glutamate receptors in hippocampal CA1 neurons. Brain Res 999:20-28.

Gahwiler BH, Brown DA (1985) GABAB-receptor-activated $\mathrm{K}^{+}$current in voltage-clamped CA3 pyramidal cells in hippocampal cultures. Proc Natl Acad Sci USA 5:1558-1562.

Goldin M, Segal M (2003) Protein kinase C and ERK involvement in dendritic spine plasticity in cultured rodent hippocampal neurons. Eur J Neurosci 17:2529-2539.

Goldin M, Segal M, Avignone E (2001) Functional plasticity triggers formation and pruning of dendritic spines in cultured hippocampal networks. J Neurosci 21:186-193.

Griffith WH, Brown TH, Johnston D (1986) Voltage-clamp analysis of synaptic inhibition during long-term potentiation in hippocampus. J Neurophysiol 55:767-775.

Huang YY, Li XC, Kandel ER (1994) cAMP contributes to mossy fiber LTP by initiating both a covalently mediated early phase and macromolecular synthesis-dependent late phase. Cell 79:69-79.

Izumi Y, Zorumski CF (1993) Nitric oxide and long-term synaptic depression in the rat hippocampus. NeuroReport 4:1131-1134.

Kapur A, Yeckel M, Johnston D (2001) Hippocampal mossy fiber activity evokes $\mathrm{Ca}^{2+}$ release in CA3 pyramidal neurons via a metabotropic glutamate receptor pathway. Neuroscience 107:59-69.

Katz B, Miledi R (1968) The role of calcium in neuromuscular facilitation. J Physiol (Lond) 195:481-492.

Kleschevnikov AM, Sokolov MV, Kuhnt U, Dawe GS, Stephenson JD, Voronin LL (1997) Changes in paired-pulse facilitation correlate with induction of long-term potentiation in area CA1 of rat hippocampal slices. Neuroscience 76:829-843.

Knight AR, Bowery NG (1996) The pharmacology of adenylyl cyclase modulation by GABAB receptors in rat brain slices. Neuropharmacology 35:703-712.

Krieger P, Hellgren-Kotaleski J, Kettunen P, El Manira AJ (2000) Interaction between metabotropic and ionotropic glutamate receptors regulates neuronal network activity. J Neurosci 50:5382-5391.
Kullmann DM, Siegelbaum SA (1995) The site of expression of NMDA receptor-dependent LTP: new fuel for an old fire. Neuron 15:997-1002.

Lamsa K, Heeroma JH, Kullmann DM (2005) Hebbian LTP in feed-forward inhibitory interneurons and the temporal fidelity of input discrimination. Nat Neurosci 8:916-924.

Lisman JE (2001) Three $\mathrm{Ca}^{2+}$ levels affect plasticity differently: the LTP zone, the LTD zone and no man's land. J Physiol (Lond) 15:285.

Lu W, Man H, Ju W, Trimble WS, MacDonald JF, Wang YT (2001) Activation of synaptic NMDA receptors induces membrane insertion of new AMPA receptors and LTP in cultured hippocampal neurons. Neuron 29:243-254.

Lu YM, Mansuy IM, Kandel ER, Roder J (2000) Calcineurin-mediated LTD of GABAergic inhibition underlies the increased excitability of CA1 neurons associated with LTP. Neuron 26:197-205.

Lynch G, Larson J, Kelso S, Barrionuevo G, Schottler F (1983) Intracellular injections of EGTA block induction of hippocampal long-term potentiation. Nature 305:719-721.

Malenka RC, Nicoll RA (1999) Long-term potentiation-a decade of progress? Science 285:1870-1874.

Malinow R, Malenka RC (2002) AMPA receptor trafficking and synaptic plasticity. Annu Rev Neurosci 25:103-126.

Malinow R, Tsien RW (1990) Presynaptic enhancement shown by wholecell recordings of long-term potentiation in hippocampal slices. Nature 346:177-180.

Markram H, Segal M (1990) Electrophysiological characteristics of cholinergic and non-cholinergic neurons in the rat medial septum-diagonal band complex. Brain Res 513:171-174.

Markram H, Lubke J, Frotscher M, Sakmann B (1997) Regulation of synaptic efficacy by coincidence of postsynaptic APs and EPSPs. Science 275:213-215.

Mellor J, Nicoll RA (2001) Hippocampal mossy fiber LTP is independent of postsynaptic calcium. Nat Neurosci 4:125-126.

Misgeld U, Klee MR, Zeise ML (1994) Differences in baclofen-sensitivity between CA3 neurons and granule cells of the guinea pig hippocampus in vitro. Neurosci Lett 47:307-311.

Misgeld U, Bijak M, Jarolimek W (1995) A physiological role for GABAB receptors and the effects of baclofen in the mammalian central nervous system. Prog Neurobiol 46:423-462.

Mott DD, Lewis DV (1991) Facilitation of the induction of long-term potentiation by GABAB receptors. Science 252:1718-1720.

Neuhoff H, Roeper J, Schweizer M (1999) Activity-dependent formation of perforated synapses in cultured hippocampal neurons. Eur J Neurosci 11:4241-4250

Nicoll RA, Malenka RC (1999) Expression mechanisms underlying NMDA receptor-dependent long-term potentiation. Ann NY Acad Sci 868:515-525.

Nowicky AV, Bindman LJ (1993) The nitric oxide synthase inhibitor, $\mathrm{N}$-monomethyl-L-arginine blocks induction of a long-term potentiationlike phenomenon in rat medial frontal cortical neurons in vitro. J Neurophysiol 70:1255-1259.

Ohno-Shosaku T, Sawada S, Yamamoto C (1998) Properties of depolarization-induced suppression of inhibitory transmission in cultured rat hippocampal neurons. Pflügers Arch 435:273-279.

Ohno-Shosaku T, Sawada S, Kano M (2000) Heterosynaptic expression of depolarization-induced suppression of inhibition (DSI) in rat hippocampal cultures. Neurosci Res 36:67-71.

Ohno-Shosaku T, Tsubokawa H, Mizushima I, Yoneda N, Zimmer A, Kano M (2002) Presynaptic cannabinoid sensitivity is a major determinant of depolarization-induced retrograde suppression at hippocampal synapses. J Neurosci 22:3864-3872.

Papa M, Bundman MC, Greenberger V, Segal M (1995) Morphological analysis of dendritic spine development in primary cultures of hippocampal neurons. J Neurosci 15:1-11.

Parker D, Grillner S (1999) Long-lasting substance-P-mediated modulation of NMDA-induced rhythmic activity in the lamprey locomotor network involves separate RNA- and protein-synthesis-dependent stages. Eur J Neurosci 11:1515-1522.

Patenaude C, Chapman CA, Bertrand S, Congar P, Lacaille JC (2003) GABAB receptor- and metabotropic glutamate receptor-dependent cooperative long-term potentiation of rat hippocampal GABAA synaptic transmission. J Physiol (Lond) 15:155-167.

Puopolo M, Belluzzi O (2001) NMDA-dependent, network-driven oscilla- 
tory activity induced by bicuculline or removal of $\mathrm{Mg}^{2+}$ in rat olfactory bulb neurons. Eur J Neurosci 13:92-102.

Santschi LA, Stanton PK (2003) A paired-pulse facilitation analysis of longterm synaptic depression at excitatory synapses in rat hippocampal CA1 and CA3 regions. Brain Res 962:78-91.

Schulz PE, Cook EP, Johnston D (1994) Changes in paired-pulse facilitation suggest presynaptic involvement in long-term potentiation. J Neurosci 14:5325-5337.

Slutsky I, Sadeghpour S, Li B, Liu G (2004) Enhancement of synaptic plasticity through chronically reduced $\mathrm{Ca}^{2+}$ flux during uncorrelated activity. Neuron 44:835-849.

Stanton PK, Winterer J, Bailey CP, Kyrozis A, Raginov I, Laube G, Veh RW, Nguyen CQ, Muller W (2003) Long-term depression of presynaptic release from the readily releasable vesicle pool induced by NMDA receptordependent retrograde nitric oxide. J Neurosci 23:5936-5944.

Taccola G, Marchetti C, Nistri A (2003) Effect of metabotropic glutamate receptor activity on rhythmic discharges of the neonatal rat spinal cord in vitro. Exp Brain Res 153:388-393.

Than M, Szabo B (2002) Analysis of the function of GABA(B) receptors on inhibitory afferent neurons of Purkinje cells in the cerebellar cortex of the rat. Eur J Neurosci 15:1575-1584.

Voronin LL, Altinbaev RS, Bayazitov IT, Gasparini S, Kasyanov AV, Saviane C, Savtchenko L, Cherubini E (2004) Postsynaptic depolarisation enhances transmitter release and causes the appearance of responses at "silent" synapses in rat hippocampus. Neuroscience 126:45-59.

Wagner JJ, Alger BE (1995) GABAergic and developmental influences on homosynaptic LTD and depotentiation in rat hippocampus. J Neurosci 15:1577-1586.

Wang J, Yeckel MF, Johnston D, Zucker RS (2004) Photolysis of postsynaptic caged $\mathrm{Ca}^{2+}$ can potentiate and depress mossy fiber synaptic responses in rat hippocampal CA3 pyramidal neurons. J Neurophysiol 91:1596-1607.

Wang JH, Stelzer A (1996) Shared calcium signaling pathways in the induction of long-term potentiation and synaptic disinhibition in CAl pyramidal cell dendrites. J Neurophysiol 75:1687-1702.

Williams JH, Errington ML, Lynch MA, Bliss TV (1989) Arachidonic acid induces a long-term activity-dependent enhancement of synaptic transmission in the hippocampus. Nature 341:739-742.

Yamamoto C, Chujo T (1978) Long-term potentiation in thin hippocampal sections studied by intracellular and extracellular recordings. Exp Neurol 58:242-250.

Yang SN, Tang YG, Zucker RS (1999) Selective induction of LTP and LTD by postsynaptic $\left[\mathrm{Ca}^{2+}\right]_{\mathrm{i}}$ elevation. J Neurophysiol 81:781-787.

Yanovsky Y, Mades S, Misgeld U (2003) Retrograde signaling changes the venue of postsynaptic inhibition in rat substantia nigra. Neuroscience 122:317-328.

Yeckel MF, Kapur A, Johnston D (1999) Multiple forms of LTP in hippocampal CA3 neurons use a common postsynaptic mechanism. Nat Neurosci 2:625-633.

Zorumski CF, Izumi Y (1998) Modulation of LTP induction by NMDA receptor activation and nitric oxide release. Prog Brain Res 118:173-182. 